\title{
EEN OPINIEPEILING ONDER ENKELE CATEGORIEËN GEBRUIKERS VAN JAARVERSLAGEN NAAR O.M. DE BEHOEFTE AAN PRESENTATIE VAN ACTUELE WAARDEN VOOR ACTIVA EN PASSIVA IN DE GEPUBLICEERDE JAARREKENING
}

\author{
door N.J.M. van Tulder')
}

\section{Inleiding}

De externe jaarverslaglegging van ondernemingen is een nogal controversiëel onderwerp dat internationaal in de belangstelling staat. Zo ook in Nederland.

$\mathrm{Na}$ het in werking treden van de Wet op de jaarrekening van ondernemingen (WJO 1971 ) zijn op verzoek van de Minister van Justitie de gezamenlijke Commis. sies Jaarverslaglegging in het leven geroepen. Hierin hebben zitting vertegen. woordigers van het accountantsberoep, van werkgevers en werknemersorganisaties. Zij hebben o.m. tot taak te formuleren op welke wijze de externe financiële verslaglegging zou dienen plaats te vinden.

In dit artikel wordt een beknopte uiteenzetting gegeven over de resultaten van een empirisch-kwantitatief onderzoek onder (potentiële) gebruikers van jaarver. slagen in Nederland. Aan het onderzoek ligt de overweging ten grondslag dat in ons land tot op heden weinig aandacht is en wordt besteed aan de meningen en wensen van diegenen voor wie de externe verslaggeving van ondernemingen wordt geacht te zijn bestemd. Zo kunnen als belanghebbenden worden aange. merkt: aandeelhouders en andere beleggers, financiële analisten, eenieder die be. roepsmatig bij de handel in effecten betrokken is, de financiële pers, bankiers, le. veranciers, werknemers, werkgevers, de overheid enz.

De onderhavige opiniepeiling was toegespitst op een zeer specifiek, maar uitermate belangrijk, onderdeel van de financiële verslaglegging $\mathrm{nl}$. de voor activa en passiva te gebruiken methode(n) van waardering.')

De doelstelling van het onderzoek kan als volgt worden samengevat: na te gaan welke waarderingsgrondslagen een aantal categorieën (potentiële) gebruikers van jaarverslagen als groep in het algemeen toegepast wensen te zien in de gepu. bliceerde jaarrekening, en verder of men o.m. behoefte heeft aan presentatie van actuele waarden voor activa en passiva.

Met opzet is gekozen voor de formulering: ,gepubliceerde jaarrekening" i.v.m. het feit dat alle groepen gebruikers daar zonder problemen kennis van kunnen nemen.

Uit hoofde van een doelmatige afbakening van het onderzoekterrein en gegeven een krap bemeten hoeveelheid mankracht en financiële middelen is de opiniepeiling beperkt tot de navolgende categorieën gebruikers: Vereniging voor de Effectenhandel, Vereniging van Beleggingsanalisten, Vereniging Effecten Be.

\footnotetext{
1) Deze opiniepeiling is tot stand gekomen bimen het kader van de leerstoelgroep Wiarde en Winst, Vakgroep Bedrijfseco noınie, Universiteit van Aınsterdam. Gaarne wil ik mijn dank uitspreken aan Prof. Dr P. A. M. van Philips i.v.m. de vele waar devolle suggesties warvan ik heb mogen jrofiteren. Uiteraard blijf de auteur verantwoordelijk voor de inhoud van dit artikel.

2) Enkele buitenlandse onderzorken in deze richting tijn die van:

Ralph W. Estes, ,An assessment of the usefulness of current cost and price-level infor mation by financial statement users". Jour nal of Accounting Research 1968. bl. 200.207.

Vincent C. Brenner, .Finaucial statement users views of the desirability of reporting current cost information". Journal of Ac comting Research 1970, bl.. 159.166.

Don. E. Garner. .The need for pricelevel and replaremeru value data", Joumal of Accountancy sept. 1972, blz. 94 e.v
} 
scherming (VEB), Nederlandse Centrale Vereniging van Beleggingsstudieclubs (NCVB) en redacteuren der financiële pers, waaronder ook begrepen de finan. cieel redacteuren van de dag. en weekbladen.

Niet in het onderzoek opgenomen zijn o.m. a) de vakbeweging i.c. de vakcen trales NVV, NKV en CNV en b) een (representatieve) doorsnede van het Nederlandse bedrijfsleven. Hoewel de financiële verslaggeving voor vakbeweging c.q. werknemers van belang moet worden geacht o.m. in verband met bedrijfsslui. tingen en ook het recentelijk gepubliceerde wetsontwerp Vermogensaanwasde. ling (VAD), konden, naar dezerzijds van hen werd begrepen, op diverse bestuur. lijke niveau's van de vakbeweging onvoldoende ter zake kundigen gevonden worden om tot een representatieve steekproef te kunnen komen. ${ }^{3}$ )

Wat het bedrijfsleven betreft moet worden opgemerkt dat het trekken van een representatieve, uiteraard gestratificeerde, steekproef uit het Nederlandse bedrijfsleven een dermate omvangrijke en problematische aangelegenheid is dat zij niet binnen het kader van dit onderzoek uitgevoerd kon worden. Overigens zij opgemerkt dat wel degelijk vertegenwoordigers van het bedrijfsleven voorko. men onder de respondenten op de enquête..$\left.^{-}\right)$Dit is een automatisch gevolg van de keuze die is gedaan m.b.t. de te enquêteren categorieën.

\section{Methode van onderzoek}

De opiniepeiling vond schriftelijk plaats in de periode 15 oktober 1975 tot en met 15 maart 1976. Twee maal werd een „reminder" verstuurd met het verzoek de enquête alsnog in te vullen en te retourneren.

De potentiële respondenten werden van het onderzoek op de hoogte gesteld d.m.v. aankondigingen in verenigingsorganen e.d., alsmede door een kort bericht in het Financieel Dagblad van 22 oktober 1975.

Alvorens tot enquêtering over te gaan werd een proefonderzoek onder ca. 30 personen gehouden om te verifiëren of het vragenformulier voldeed aan zekere normen. Onder meer werd getest of de vragen eenduidig, volledig, niet-suggestief en overzichtelijk gerangschikt waren. Pas na evaluatie van de uitkomsten van het proefonderzoek werd het definitieve vragenformulier vastgesteld.

Uit de te onderzoeken gebruikerspopulaties werden aselecte, systematische, steekproeven getrokken. ') Hierbij zij aangetekend dat de NCVB en de Financiële Pers op een afwijkende wijze zijn onderzocht. De aan de NCVB gelieerde beleg. gingsstudieclubs zijn alle in hun geheel geënquêteerd in die zin dat elke vereniging slechts één vragenlijst behoefde in te vullen. M.a.w. deze studieverenigingen zijn collectief in de opiniepeiling opgenomen. De Financiële Pers bleek een groep te zijn die qua omvang (ca. 60 personen) in aanmerking kwam integraal geënquê. teerd te worden.

In totaal werden 420 vragenlijsten verstuurd waarvan er 249 ofwel 59\% terug ontvangen werden. Circa $19 \%$ der respons werd bij verwerking en analyse buiten

\footnotetext{
3) Vlak voor het ter perse gaan van dit artikel kwam een recente publikatie van de Federarie Nederlandse Vakbeweging rer beschikking: „OPEN BOEK, Een nota over de behoefte van werknemers aan informatie over hun onderneming", juli. Hierin wordt vrijwel voorbijgegaan aan de problematiek van waardering van activa en passiva in de externe jaarrekening. Er wordt slechts gepleit voor meer uniformiteit t.a.v. de toegepaste grondslagen van wardering en winstbepaling.

4) Met name onder de leden van de Vereniging voor de Effectenhandel en de Vereniging Effecten Bescherming komen veel representanten van het bedrijfsleven voor.

5) Vanaf een willekeurige letter uit het alfabet werd uit het desbetreffende ledenbestand steeds iedere $k$ de kaart getrokken Het getal $k$ is het quotienc van de populatieomvang en de steekproefomvang.
} 
beschouwing gelaten omdat de geënquêteerden zichzelf niet voldoende compe. tent achtten ofwel vanwege onvolledigheid of inconsistentie in de antwoorden. Uiteindelijk resteerde er een netto (bruikbare) respons van ca. $40 \%$.

$\mathrm{Na}$ het afsluiten van de periode van inzamelen der primaire (ruwe) data vond bewerking plaats per computer van de Stichting Academisch Rekencentrum Am. sterdam (SARA).

\section{Omschrijvingen der gehanteerde waarderingsgrondslagen}

In de enquête stonden t.a.v. de waarderingsgrondslagen voor activa en passiva 5 keuzemogelijkheden vermeld, die als volgt omschreven kunnen worden.

I. Waardering op basis van historische kosten of lagere marktwaar. de (,minimumwaarderingsregel”)

II. Waardering op basis van historische kosten of lagere marktwaar. de, gecorrigeerd voor algemene koopkrachtveranderingen")

III. Waardering op basis van vervan. gingswaarde of lagere opbrengst. waarde

IV. Waardering op basis van indirec. te opbrengstwaarde

V. Waardering op basis van directe opbrengstwaarde

- de destijds betaalde prijs ofwel uit gaafprijs, tenzij de marktwaarde la. ger ligt

- de uitgaafprijs tenzij de marktwaar. de lager ligt, per het eind van de periode gecorrigeerd met een alge. meen prijsindexcijfer

- de actuele prijs op de (in. koop)markt tenzij de opbrengstwaarde lager ligt

- de contante waarde van de toe. komstige netto ontvangsten (cash flows)

- de actuele opbrengstprijs op de (verkoop)markt

Het is niet de bedoeling van dit artikel nader in te gaan op de theoretische achtergronden en pro en contra argumenten terzake van de onderscheiden waarderingsgrondslagen. De mérites der genoemde methoden worden bekend verondersteld.

\section{Enquete-resultaten ${ }^{7}$ )}

A. Beoordeling huidige en toekomstige verslaggeving

De attitude t.o.v. de huidige en toekomstige verslaggeving werd met behulp van de volgende vraagstellingen getest:

$V R A A G 1$ "Verschaffen balans, verlies- en winstrekening en toelichting zoals zij op dit moment in het algemeen voorkomen in gepubliceerde jaarverslagen, tezamen voldoende informatie voor het gebruik dat U ervan maakt?"
JA $\cdot 39 \%$
NEEN $\cdot 61 \%$

VRAAG 2 "Vindt $\mathrm{U}$ dat in het algemeen de jaarrekening voldoende informa. tie verstrekt omtrent de wijze waarop de toegepaste waarderings.

6) Het koopkrachtcorrectiesysteem wordt algemeen als efn correctiemethode en niet als een aparte waarderingsgrondslag beschouwd.

Alle resultaten zijn weergegeven in procenten van de totale netto respons. 
grondslagen invloed uitoefenen op vermogen en resultaat?" JA $\cdot 21 \%$ NEEN $\cdot 79 \%$

VRAAG 3 „Denkt $\mathrm{U}$ dat de informatieve betekenis van de meeste gepubliceerde jaarverslagen vergroot zal worden door toepassing van andere waarderingsgrondslagen in plaats van of naast historische kosten?" JA $\cdot 92 \%$ NEEN $\cdot 8 \%$

In vraag 4 van de enquête werd verzocht om een expliciet standpunt inzake de keuze van de wenselijk geachte waarderingsgrondslag(en) voor activa en passiva in de jaarrekening. Onderscheiden werd naar: duurzame en vlottende activa (balans) en kosten van duurzame resp. vlottende activa (resultatenrekening.). ${ }^{8}$ ) In tabel 1 staat procentueel vermeld welke waarderingsgrondslagen men koos voor duur. zame resp. vlottende activa in de balans. Tabel 2 verstrekt dezelfde informatie omtrent kosten van duurzame resp. vlottende activa in de resultatenrekening.

Tabel 1

BALANS

GRONDSLAG

$\begin{array}{cc}\text { Duurzame } & \text { Vlottende } \\ \text { activa } & \text { activa } \\ (p c t) & (p c t)\end{array}$

Historische kosten

Koopkrachtcorrectie

Vervangingswaarde

Indirecte opbrengstwaarde

Directe opbrengstwaarde
7

10

38

4

6

16

19

$100 \%$

\section{7}

9

30

4

19

Vervangingswaarde

+ historische kosten

Overige combinaties ${ }^{9}$ )

TOTAAL

11

20

Wat duurzame activa betreft wenst $63 \%$ der respondenten één waarderings. grondslag en $37 \%$ méér grondslagen gehanteerd te zien.

Voor vlottende activa geldt dat $68 \%$ opteert voor één waarderingsgrondslag tegen $32 \%$ voor méér.

\footnotetext{
8) Activa zoals deelnemingen, vorderingen en liquide midclelen zijn buiten beschouwing gelaten. Aanleiding hiertoe was de veronderstelling dat de onderhavige waarderingsgrondslagen voomamelijk gebruikt zullen worden voor materiéle activa.
} 
RESULTATENREKENING

\begin{tabular}{lcc}
\hline GRONDSLAG & $\begin{array}{c}\text { Kosten van } \\
\text { Duurzame } \\
\text { activa } \\
(p c t)\end{array}$ & $\begin{array}{c}\text { Kosten van } \\
\text { Vlottende } \\
\text { activa } \\
(p c t)\end{array}$ \\
\hline $\begin{array}{l}\text { Historische kosten } \\
\text { Koopkrachtcorrectie }\end{array}$ & 7 & 8 \\
$\begin{array}{l}\text { Vervangingswaarde } \\
\text { Indirecte opbrengstwaarde }\end{array}$ & 11 & 7 \\
$\left.\begin{array}{l}\text { Directe opbrengstwaarde } \\
\text { Vervangingswaarde } \\
\text { + Historische kosten } \\
\text { Overige combinaties }\end{array}{ }^{y}\right)$ & 49 & 32 \\
17.1 & 7 & 5 \\
TOTAAL & 16 & 20 \\
\hline
\end{tabular}

Wat betreft de kosten van duurzame activa heeft $68 \%$ een voorkeur voor toepassing van één waarderingsgrondslag en $32 \%$ voor méér grondslagen. Bij de kosten van vlottende activa wenst $71 \%$ der geënquêteerden één waarderingsgrondslag gehanteerd te zien tegen $29 \%$ méér grondslagen.

Hieronder staan de percentages respondenten vermeld die wel resp. geen identieke grondslag of grondslagencombinatie kozen voor duurzame en vlottende activa in de balans, kosten van duurzame en vlottende activa in de resultatenreke. ning, en totaal, d.w.z. balans en resultatenrekening tezamen genomen.

\section{BALANS}

Identieke waarderingsgrondslag(en) voor duurzame en vlottende activa $\quad 51 \%$ Niet identiek

RESULTATENREKENING

Identieke grondslag(en) v. kosten van duurzame en vlottende activa $\quad 58 \%$

Niet identiek

TOTAAL (Bal. + Res.rek.)

Identieke waarderingsgrondslag(en) in zowel de Balans

als de Resultatenrekening

Niet identiek

Uit de beantwoording van vraag 4 kan verder nog het volgende worden afgeleid:

\footnotetext{
4) Door de respondenten zijn de grondslagen op uiteenlopende wijze gecombineerd. in de meeste combinaties komt vervan gingswaarde en/of directe opbrengstwaarde voor, zodat gesproken worden van een duidelijke tendens naar actuele waarden.
} 
$82 \%$ van de onderzochte gebruikers wenst op enigerlei wijze toepassing van vervangingswaarde in de jaarrekening.

$37 \%$ van de onderzochte gebruikers wenst op enigerlei wijze toepassing van historische kosten in de jaarrekening.

$34 \%$ van de onderzochte gebruikers wenst op enigerlei wijze toepassing van $d i$ recte opbrengstwaarde in de jaarrekening.

$32 \%$ van de onderzochte gebruikers wenst op enigerlei wijze toepassing van koopkrachtcorrectie in de jaarrekening.

$14 \%$ van de onderzochte gebruikers wenst op enigerlei wijze toepassing van indirecte opbrengstwaarde in de jaarrekening.

"Op enigerlei wijze" wil in dit geval zeggen dat men toepassing van de betreffende waarderingsgrondslag wenst op tenminste één van de genoemde posten in de balans en/ of resultatenrekening, t.w. (kosten van) duurzame resp. vlottende ac. tiva.

Indien de gegevens uit vraag 4 tenslotte gecombineerd worden dan blijkt dat $71 \%$ der geënquêteerden van mening is dat in de jaarrekening als geheel méér dan één grondslag moet worden toegepast. Daarvan kiest dan $63 \%$ voor twee waarderingsgrondslagen.

\section{B. Betrouwbaarheid der gegevens}

In vraag 5 van de enquête werd men verzocht aan te geven in hoeverre men vond dat de verslagleggingsgegevens op basis van de 5 genoemde waarderingsgrond. slagen betrouwbaar kunnen worden geacht. Waardering van de betrouwbaar. heid was mogelijk in een schaal van 1 tot en met 5 , waarbij 5 de hoogste betrouw. baarheid uitdrukte. In tabel 3 staan de gemiddelde betrouwbaarheidswaarderin gen en de moduswaarnemingen per grondslag vermeld.

Tabel 3

Gemiddelden en moduswaarnemingen per grondslag

grondslag gemiddelde modus

$\begin{array}{lll}\text { historische kosten } & 2.80 & 1 \\ \text { koopkrachtcorrectie } & 3.00 & 3 \\ \text { vervangingswaarde } & 3.93 & 5 \\ \text { indir. Opbrengstw. } & 2.18 & 1 \\ \text { directe opbrengstw. } & 3.19 & 5\end{array}$

In vraag 6 werd aan de orde gesteld of men de mening toegedaan was dat de antwoorden op de vragen $1 \mathrm{t} / \mathrm{m} 5$ afhankelijk zijn van een onderscheiding naar categorieën bedrijven. Ca. $55 \%$ der ondervraagden gaf hierop een bevestigend antwoord. Deze laatsten werden vervolgens verzocht vraag 7 in te vullen.

\section{VRAAG 7}

„Specificeert $U$ hieronder in hoeverre $U$ van mening bent dat de in vraag 5 genoemde gegevens betrouwbaar zijn voor de volgende categorieën: Handelsbe drijven, Industriële bedrijven en Financiële instellingen."

In tabel 4 staan de resultaten van deze vraag samengevat. 
Tabel 4

Gemiddelden en moduswaarnemingen per grondslag,

gesplitst naar categorie bedrijuen.

\begin{tabular}{lcccccc}
\hline grondslag & \multicolumn{2}{c}{ Handelsbedrijven } & \multicolumn{2}{c}{ Industriële bedr. } & \multicolumn{2}{c}{ Financiële instel. } \\
\hline & gemiddelde & modus & gemiddelde & modus & gemiddelde & modus \\
\hline historische kosten & 3.04 & 5 & 2.77 & 1 & 3.72 & 5 \\
koopkrachtcorrectie & 2.96 & 3 & 3.00 & 3 & 3.08 & 3 \\
vervangingswaarde & 3.80 & 5 & 4.03 & 5 & 3.21 & 4 \\
indirecte opbrengstw. & 2.21 & 1 & 2.44 & 1 & 2.88 & 2 \\
directe opbrengstw. & 3.62 & 3 & 2.93 & 3 & 3.06 & 5 \\
\hline
\end{tabular}

De rangorde der grondslagen als resultante van de betrouwbaarheidsopties weergegeven in tabel 3 is als volgt:

1. vervangingswaarde (meest betrouwbaar)

2. directe opbrengstwaarde

3. koopkrachtcorrectie

4. historische kosten

5. indirecte opbr.w. (minst betrouwbaar)

Indien de antwoorden uit vraag 5 worden uitgesplitst naar categorie bedrijven dan blijkt de rangorde niet steeds dezelfde compositie te hebben voor elk van de drie groepen afzonderlijk. Met name de financiële instellingen vormen een speciaal geval. Consensus bestaat t.a.v. de vaststelling dat voor deze groep van ondernemingen historische kosten als meest betrouwbare waarderingsgrondslag moet worden aangemerkt., Voor handels. resp. industriële bedrijven gelden vervangingswaarden als de meest adequate waardering.

\section{Wijze van presentatie}

In vraag 8 van de enquête werd men verzocht aan te geven welke gekozen waarderingsgrondslag(en) men als hoofd-of basisinformatie en welke men als aanvul. lende of extra informatie gepresenteerd wenste te zien in de externe jaarreke. ning. De volgende omschrijvingen werden daartoe gehanteerd:

hoofd/basisinformatie = de cijferopstelling van de balans en resultaten. rekening

aanvullende/extra informatie = de gegevens verstrekt in de toelichting of als bijlage (e.g. als „supplementary statement”)

Uit de beantwoording van vraag 4 is reeds naar voren gekomen dat men meer. dere waarderingsgrondslagen wenst te zien toegepast. De uitkomsten van vraag 8 tonen aan dat men in meerderheid vervangingswaarde als basisgrondslag wenst en soms historische kosten als aanvullende informatie.

In vraag 9 werd men gevraagd in het kort te omschrijven waarom men ge. kozen had voor de in vraag 4 aangekruiste waarderingsgrondslagen. Aangezien het onderzoek primair kwantitatief gericht was, zijn deze motiveringen min of meer als ,bijprodukt” ontstaan en tevens niet zo diepgaand. Derhalve zullen zij hier niet worden vermeld. 


\section{Stellingen}

Aan het eind van het vragenformulier waren een viertal stellingen opgenomen die de intentie hadden de impliciete uitspraken in de enquête wat meer reliëf te geven.

STELLING 1 „Historische kosten kunnen, indien als enige grondslag toegepast, heden ten dage niet meer als een adequate grondslag voor de jaarverslaglegging beschouwd worden"

MEE EENS - $92 \% \quad$ NIET MEE EENS - $8 \%$

STELLING 2 „Een nationaal overheidsorgaan zou de verslagleggingspraktijk en de grondslagen voor de financiële verslaglegging moeten reguleren"

MEE EENS - $40 \% \quad$ NIET MEE EENS - $60 \%$

STELLING 3 ,Indien de verslaglegging plaatsvindt op basis van andere dan historische kosten, zou de accountantsverklaring door haar formule. ring dienen aan te duiden dat het desbetreffende verslag een meer getrouw beeld van resultaat en vermogen oplevert"

MEE EENS - $67 \%$ NIET MEE EENS - 33\%

STELLING 4 „Art. 5, lid 1, Wet op de Jaarrekening van Ondernemingen luidt: „De grondslagen waarop de waardering van activa en passiva en de bepaling van het resultaat berusten, voldoen aan normen die in het maatschappelijk verkeer als aanvaardbaar worden be. schouwd".

Stelling: De inhoud van art. 5, lid 1, W.J.O., dient vervangen te worden door èen formulering met een uitgesproken voorkeur voor vervangingswaarde en/of koopkrachtcorrectie in de jaarrekening. MEE EENS - $64 \%$ NIET MEE EENS - 36\%

\section{Evaluatie en kwalificatie}

Gezien de context van de onderhavige opiniepeiling ben ik mij terdege bewust van de beperkingen die eraan verbonden zijn. In het bijzonder betreft dit de gevolgde methode van onderzoek. Indien in plaats van een (hoofdzakelijk) kwantitatieve, schriftelijke enquête gebruik gemaakt zou zijn van kwalitatieve interviews, waren de resultaten ongetwijfeld van grotere informatieve betekenis geweest dan nu het geval is. Als lacune in het huidige onderzoek kan o.m. worden aan. gemerkt dat de respondenten zich nauwelijks hebben behoeven te verdiepen in de theoretische aspecten en de (mogelijk vérstrekkende) consequenties van de verlangens die zij op tafel leggen. Voor een onderzoeksstructuur als hierboven geschetst waren de financiële middelen echter ontoereikend. Een en ander heeft tot gevolg dat deze opiniepeiling slechts als een eerste oriëntatie op dit gebied kan worden beschouwd.

Behalve de gesignaleerde tekortkomingen in de methode van onderzoek moet bij interpretatie van de hiervoor beschreven uitkomsten rekening worden gehouden met de navolgende aspecten en begrenzingen.

In de eerste plaats zijn niet alle denkbare groepen gebruikers van jaarverslagen 
in het onderzoek vertegenwoordigd.

Ten tweede is ca. $40 \%$ bruikbare respons gekomen op de enquêtte, hetgeen een onbekende non-respons afwijking kan inhouden.

$\mathrm{O}_{\mathrm{p}}$ de derde plaats isgebruik gemaakt van een zeer ruwe, ongedetailleerde indeling in waarderingsgrondslagen, activa en passiva, en categoriëen bedrijven. Een meer verfijnde benadering zou ongetwijfeld een meer genuanceerd beeld hebben opgeleverd.

Ten vierde en laatste zijn bij de berekening der resultaten geen wegingscoëfficiënten toegepast naar rato van het gewicht der onderscheidene categoriëen in het totaal van de onderzochte groepen. Met name het inschatten van de relatieve betekenis der financiële pers zou arbitrair geweest zijn. ${ }^{10}$ )

Praktisch gesproken geven de resultaten slechts de opvattingen weer van de respondenten, en voorzover zij representatief geacht kunnen worden, de mening van de onderzochte categorieën gebruikers.

\section{Samenvatting}

In deze opiniepeiling werden een aantal groepen (potentiële) jaarverslagengebruikers empirisch-kwantitatief onderzocht, t.w. leden van resp. de Vereniging voor de Effectenhandel, de Vereniging van Beleggingsanalisten, de Vereniging Effec. ten Bescherming, de Nederlandse Centrale Vereniging van Beleggingsstudieclubs en de financiële Pers. Deze groepen worden verondersteld representatief te zijn voor de volgende categorieën gebruikers van jaarverslagen: aandeelhouders, beleggingsanalisten, bankiers, beroepsmatig betrokkenen bij de handel in effecten en financieel redacteuren.

Het doel van de opiniepeiling was: een aantal (potentiële) categorieën gebruikers van jaarverslagen te onderzoeken op wensen t.a.v. toe te passen waarderings. grondslagen en tevens de behoefte aan actuele waarderingen te testen. Daarbij werd het onderzoekgebied beperkt tot gepubliceerde jaarverslagen i.v.m. de algemene verkrigbbaarheid van deze verslagen.

De meeste respondenten blijken voorstander te zijn van toepassing van actuele waarden. Daarbij wordt een voorkeur uitgesproken voor vervangingswaarden. Een voorbehoud dient echter gemaakt te worden t.a.v. financiële instellingen. De respondenten op vraag 7 zijn van mening dat voor deze laatsten historische kos. ten het meest betrouwbaar moeten worden geacht.

Verder spreken de meeste respondenten voorkeur uit voor toepassing in de jaarrekening van meerdere waarderingsgrondslagen, waarbij dan historische kosten soms aantrekkelijk worden geacht als supplementaire informatie. Het is opvallend dat, alhoewel directe opbrengstwaardegegevens betrouwbaarder worden geacht dan historische kosten-gegevens, toch geopteerd wordt voor historische kosten als aanvullende informatie. Mogelijk is dit te verklaren uit de wens tot onderlinge vergelijkbaarheid te komen. Veelal zijn externe verslagen immers opgesteld op basis van historische kosten. Door de meerderheid der respondenten wordt de huidige verslaggeving als onbevredigend ervaren. Men is van mening dat onvoldoende informatie verstrekt wordt omtrent de wijze waarop de toege.

\footnotetext{
11) De invloed van de mening der linanciële pers kan wan grotere betekenis worden geach dinn is af te leiden uit de absolute omvang van deze groep.
} 
paste waarderingsgrondslagen invloed uitoefenen op vermogen en resultaat.

Het toepassen van andere waarderingsgrondslagen naast of in plaats van his. torische kosten zal de informatieve waarde van de jaarrekening naar veler me. ning vergroten. Bijna alle geënquêteerden (ca. 92\%) onderschrijven de stelling dat historische kosten, indien als enige waarderingsgrondslag toegepast, niet adequaat kunnen worden geacht in het kader van de jaarverslaglegging. De gedachte aan een overheidsorgaan ter regulering van de verslagleggingspraktijk en van de grondslagen voor de financiële verslaglegging wordt in meerderheid afgewezen.

Ca. $66 \%$ van de respondenten is de mening toegedaan dat de accountantsverklaring door haar formulering zou moeten aanduiden dat indien de externe verslaglegging plaatsvind op basis van actuele waarden ") een meer getrouw beeld van resultaat en vermogen wordt verstrekt dan ingeval van toepassing van louter historische kosten.

Tenslotte blijkt men in meerderheid een modificatie van de WJO te wensen in die zin dat art. 5, lid 1, vervangen wordt door een formulering waarin voorkeur wordt uitgesproken voor vervangingswaarden en/of koopkrachtcorrectie.

\section{BIJLAGE}

\section{Functie-indeling der respondenten}

Hieronder volgt een opsomming van de functieomschrijvingen der respondenten als mogelijke indicatie voor de "financial sophistication".

Alleen die personen zijn vermeld, wier antwoorden verwerkt konden worden, m.a.w. de bruikbare respons.

$\begin{array}{lc}\text { FUNKTIE-OMSCIRIJVING } & \text { AANTAL } \\ \text { president-commissaris } & 1 \\ \text { commissaris } & 4 \\ \text { president-directeur } & 1 \\ \text { directeur } & 21 \\ \text { adjunct-directeur } & 2 \\ \text { hoofd interne accountantsdienst } & 1 \\ \text { accountant } & 3 \\ \text { bedrijfseconoom } & 4 \\ \text { hoofd administratie } & 4 \\ \text { hoofd afd. beleggingsonderzoek } & 2 \\ \text { produkt manager } & 2 \\ \text { beleggingsmanager } & 1 \\ \text { hoekman Amsterdamse Effectenbeurs } & 2 \\ \text { stafemployé } & 6 \\ \text { beleggingsdeskundige/adviseur/analist } & 22 \\ \text { commissionnair } & 2 \\ \text { financieel redacteur } & 25 \\ \text { belegger (niet nader omschreven) } & 33 \\ \text { onbekend } & 34 \\ \text { Totaal (bruikbare) respons: } & 170 \text { personen }\end{array}$

11) Welke grondslagen hier bedoeld zijn valt nich alan te geven. In de enquète werd hiernatr niel gevraagd. 